\title{
Research of Commercial Cluster Development Risk Estimate Base on Business Model Innovation
}

\author{
Zhang Li \\ School of business, Shandong Yingcai University, Jinan, China 250104
}

Keywords:Business Model, Commercial Cluster, Commercial Cluster, Risk

\begin{abstract}
Business model innovation is helpful to consumer and company because of price, transaction time, convenience, and company's cost, but it may bring business firms of commercial cluster more risk when the client change their purchase channel. This paper presents a risk estimate for commercial cluster development using Random Variation of demand, to estimate the risk loss of demand fluctuation for the commercial cluster, and adopting Logit Model and Maximum Likelihood Method to estimate demand fluctuation because of business model innovation. Base on these two methods, we can get the approach to effectively estimate the incidence that the business model innovation would bring risk to commercial cluster, then, we can give the early warning to the commercial cluster and explore the ways according to the risk probability.
\end{abstract}

\section{Introduction}

With the development of logistics industry and information technology, online retail has become an important direct channel adopted by more and more companies ${ }^{[1]}$, because consumers are more likely to purchase certain product categories than others via direct channel, then some industries have seen a faster growth in dual channel supply chains than others. Dual channels could mean more shopping choices and price savings to customers ${ }^{[2]}$. Base on this, business model may be changed.

Business model was considered as a new perspective of firm strategy by most scholars, but have different understanding on business model, such as the reference consider that business is a structural model that means how core firm transacts with consumers and suppliers. But the others believe that business is a construct of product, service and information ${ }^{[3]}$, and describe business model as a story of firms how to operate and increase profit ${ }^{[4]}$. While the other thinks business model supplies a consistency framework that takes technology as input and generates profitable and sustainable revenue by transfer mechanism of customer and market ${ }^{[5]}$. The references presents business model is an expected set to get business success in the changing environment ${ }^{[6]}$, and defines that a business model is a conceptual tool that contains a set of elements and their relationships and allows expressing the business logic of a specific firm ${ }^{[7]}$.

The business model concept also has been addressed in the domains of innovation and technology management. In addition to adopting business models to facilitate technological innovation and the management of technology, firms can view the business model itself as a subject of innovation ${ }^{[8]}$. It introduce the notion of open innovation as a mode of innovation in which firms, rather than relying on internal ideas to advance business, look outside their boundaries in order to leverage internal and external sources of ideas ${ }^{[9]}$. A concept similar to open innovation is collaborative entrepreneurship, which is "the creation of something of economic value based on new jointly generated ideas that emerge from the sharing of information and knowledge” ${ }^{[10]}$. Open innovation requires the adoption of new, open business models designed for sharing or licensing technologies ${ }^{[11]}$. The business model itself can become part of intellectual property ${ }^{[12]}$. Open business models, apart from being a subject of innovation, may prompt additional business model innovation in complementary markets as a consequence of the reconfiguration of downstream activities and capabilities ${ }^{[13]}$.

From the point of view of the focal firm, the activities of external innovators can be organized as a collaborative community or as a market ${ }^{[14]}$, which in turn implies different business model configurations: in the former (community), members are often willing to collaborate and work for 
free, while in the latter (market) innovators develop multiple competing varieties of complementary goods, components, or services, with little cooperation among them.

There is an increasing consensus that business model innovation is key to firm performance. A significant number of scholars focus on business model innovation as a vehicle for corporate transformation and renewal ${ }^{[15-17]}$. The reference have identified barriers to business model innovation in existing firms, such as the configurations of assets and processes, which may be subject to inertia, as well as the cognitive inability of managers to understand the value potential of a new business model ${ }^{[18]}$. How can these barriers be overcome? Some scholars contend that the business model takes shape through a process of experimentation ${ }^{[19,20]}$, which might differ for different organizations in different competitive landscapes. For example, propose a three-step process of analysis to help managers in knowledge-intensive organizations improve their business models ${ }^{[21]}$.

A specific leadership agenda might be required for business model innovation ${ }^{[22]}$. To overcome the rigidity that accompanies established business models, the reference propose that companies be made more agile, which can be achieved by developing three meta-capabilities ${ }^{[23]}$ : strategic sensitivity, leadership unity, and resource flexibility. In a similar vein, the other highlight how the effective management of complex business models "depend[s] on leadership that can make dynamic decisions, build commitment to both overarching visions and agenda specific goals, learn actively at multiple levels and engage conflict" ${ }^{\text {[24] }}$. The reference also emphasizes the importance of the behavioral aspects involved in business model innovation. They suggest that mutual engagement and organizational justice are needed and that managers should focus on the relational dynamics at the level of informal organization ${ }^{[25]}$.

Since business model innovation is so important for firms according to these literatures and the current context of logistics and e-business development, it is inevitable for present firms, of course including in commercial clusters, because commercial cluster is positively related to firm's business model. Therefore, the traditional commercial cluster faces to a serious challenge when the firm's business model has to innovate to a quite new style. But in China, there are many commercial clusters distributed in different cities, if the business model is changed into a new one, it means many firms of commercial clusters may fall into dilemma, even go bankrupt. However, given the economic development level, infrastructure, geographical environment, consumption concept and other social conditions in China, the probability of risk or challenge may be low. So to forecast the probability of risk seems to be critical.

\section{Methodology}

With the development of logistics system and information technology, the probability of business model change and distribution channel innovation will increase, then more and more firms adopt the direct sale model by online using advanced information technology, so it bring the business companies of commerce cluster much threat. Facing this future threat, commerce cluster should estimate the risk probability firstly. This paper forecasts the risk probability base on Random Variation of demand.

First, we suppose $X$ is the demand quantity of clients from commerce cluster $(X \in[0,+\infty]) . f(x)$ is the probability density function of $X$, and $\varepsilon$ as a constant is the theoretical predicted value. The difference between actual demand and theoretical predicted value results in demand fluctuation, and we define the demand fluctuation as $n=|x-a|,(\pi \in[0,+\infty])$. Then we can get the probability density function of $n$ as $t h(\pi)$ and the probability of demand fluctuation base on $t a(x)$ and Linear Properties. The detail is as following.

Supposing $f(\pi)$ is the probability density function of $\pi$, then

$$
f(\pi)=p(n \leq \pi)=p d x-r \mid s)
$$




$$
=p(\varepsilon-\pi \leq X \leq \varepsilon+\pi)=\int_{\varepsilon-\pi}^{\varepsilon+\pi} f(x) d x,
$$

As we know, $\varepsilon+\pi>0$.

when $\pi-\pi<\mathrm{j}$, it means $\pi>\varepsilon$, so

$f_{n}(\pi)=p(n \leq \pi)=\int_{\varepsilon-\pi}^{\varepsilon+\pi} \mathrm{E}(x) d x=\int_{0}^{\varepsilon+\pi} \mathrm{E}(x) d x$,

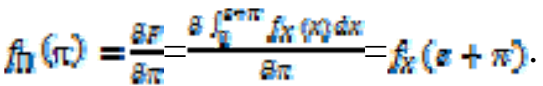

When $a-\pi \geq 0$, it means $0 \leq \pi \leq a$,

So $f \mathrm{~h}(\pi)=p(\pi \mathrm{s} \pi)=\int_{\varepsilon-\pi}^{\mathrm{s} \pi} \mathrm{f} f(x) d x$,

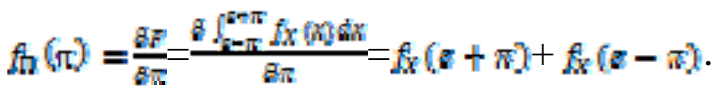

Theory, we can get the probability density function of $\pi$ as following.

$$
f(\pi)=\left\{\begin{array}{l}
f_{x}(a+\pi)+k(a-\pi), 0 \leq \pi \leq s \\
f_{x}(a+\pi),
\end{array}\right.
$$

In this paper, we attempt to explore the loss of business firms with demand fluctuation of clients. As following Fig.1, is one part of supply chain, including in manufacturer (M), business firm of commerce cluster (B), and client (C). We can ensure the relation between the demand and the risk probability of demand fluctuation base on formula (1), but it is not enough, we also need the method to measure the risk loss to find out the risk degree.

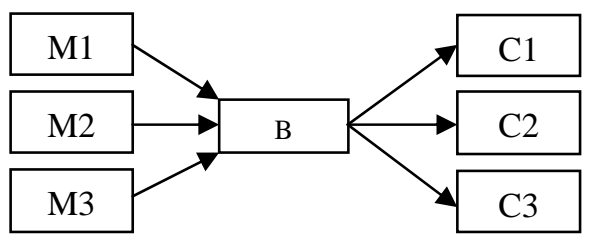

Fig.1. Inventory Cost system of Supply Chain

Before analyzing the risk loss and to simplify the complicated conditions, we suppose that (1) there is only one commerce cluster consists of many business firms, and a firm only supplies one product, (2) the demand of clients is random, (3) business firms order goods base on predicted value for demand.

According to literatures, inventory cost usually consists of purchasing cost, stockholding cost, and inventory shortage cost. To business firms, the total inventory cost is as following.

$C=C^{n}+C^{A}+C^{V}, \quad C^{n}=C_{r}+C_{t} Q_{d}$

If $x \approx f(x)$, then

$$
\begin{aligned}
& C^{n}=C_{r}+C_{t} Q_{d}, \quad C^{H}=\int_{0}^{Q_{2}} C_{\varepsilon_{2}}\left(Q_{d}-x\right) f(x) d x, \quad C^{v}=\int_{D}^{Q_{2}} C_{v}\left(x-Q_{d}\right) f(x) d x \text {, and }
\end{aligned}
$$

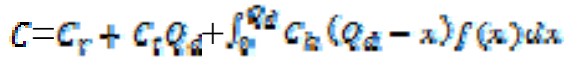

$$
\begin{aligned}
& +\int_{0}^{Q_{d}} C_{v}\left(x-Q_{d}\right) f(x) d x
\end{aligned}
$$

According to assumption (3), because business firms order goods base on predicted value for demand, $\wp_{\AA}=\approx$, then formula (2) can be changed into following formula.

$$
\begin{aligned}
& c=c_{r}+c_{\tau} a+\int_{0}^{c} c_{b}(e-x) f(x) d x \\
& +\int_{0}^{a} c_{v}(x-z) f(x) d x
\end{aligned}
$$

It should be noted, if there is no demand fluctuation, the business firm's predicted value for demand equals to the actual demand quantity $\left(z^{=} x\right)$. Meanwhile, business firm order goods according to the predicted value for demand, so $s=x=Q_{\alpha}$. Therefore, under the condition of no demand fluctuation, the total inventory cost of business firms is as following. 


$$
c=c_{r}+c_{t} a+\frac{1}{2} c_{5} a
$$

So we can get the risk loss of demand fluctuation by formula (3) and (4).

$\Delta C=\int_{0}^{2} c_{\mathrm{S}}(a-x) f(x) d x$

$+\int_{0}^{2} C_{v}(x-z) f(x) d x-\frac{1}{2} C_{2} z$

c: Total inventory cost of business firm,

$C^{R}$ : Purchasing cost of business firm,

$C^{H}$ : Stockholding cost of business firm,

$C^{V}$ : Inventory shortage cost of business firm,

$C_{\text {r }}$ : Purchase cost of one time of business firm,

$C_{\sharp}$ : Transport cost of unit product from manufacturer to business firm,

$c_{\mathrm{h}}$ : Stockholding cost of unit product of business firm,

$\mathrm{C}_{\mathrm{n}}$ : Inventory shortage cost of unit product of business firm,

$Q_{\varepsilon}$ : Order quantity of business firm,

$z$ : Predicted value for demand,

$x$ : Demand quantity of client for business firm in an order cycle time of business firm,

$f(x)$ : Probability density function of $x$.

Base on the Random Variation Model, we can know the business firm's risk loss process as formula (5), and we can also find that the loss risk depends on $s$ (Predicted value for demand) and $x$ (Demand quantity of client in an order cycle time of business firm). It means that the client's actual demand quantity is critical to business firm's cost and performance. But the key issue of $x$ depends on the business model of manufacturers. If the manufacturers change their distribution channel into multichannel or direct marketing channel by online or other innovation forms, according to the literatures, it will bring consumers more benefit of convenience, time, price, etc., then the consumers will prefer to purchase by direct channel.

There is a key problem that is what percentage about $x$ in $x^{T}$ (Total demand of a product in the entire market). If the percentage level is high, it means that consumers purchase from business firms of commercial cluster largely. On the contrary, even $\Delta C$ is low, if the clients interest in new marketing channel and buy the products by online, the business firms of commercial cluster are still facing much risk that will impede their development. So $\Delta C$ is not the only enough condition to estimate the development risk of commercial cluster base on the business model innovation. We need to know the parameter $x$. But the parameter $x$ is related to the manufacturer's business model, and it means that we should estimate $x$ according to the manufacturer's business model, otherwise, we can't get the Af, and we would not know the development risk of commercial cluster. The detail of estimating $x$ is as following process.

$x_{i}=q_{i} \%$

Here,

$x_{i}$ : The client $i$ 's purchasing quantity from business firms of commercial cluster for a kind of product,

$q i$ : Respondent $i$ 's total purchasing quantity (units/year) of the product. 
pi: Respondent $i$ 's purchasing choice probability from business firms of commercial cluster after the manufacturers changing their business model into multichannel or direct marketing channel.

$x_{i}$ is the individual demand quantity, and transform it to aggregate level to a multiple linear regression equation, as formula (7):

$$
x=\left(\frac{T}{q}\right) \Sigma i-19 t
$$

$T$ denotes the total product quantity of the products per year for the entire market; $Q$ means the total quantity of the products per year summed over the sample.

Path: "scales up" the sample of respondents to the population level according to $T / Q$.

So, to obtain $\mathbb{P}$ is the critical step, because other variables can be known easily by investigation and transaction records. According to some literatures, the scholars used Logit models to estimate customer response ${ }^{[26]}$, so here we adapt Logit Model to get $p_{i}$ for the client's decreasing choice probability.

Taking into account clients' purchasing preference $\left(u_{i}\right)$ from business firms of commercial cluster, $p_{i}$ can be described as following formula (8).

We can obtain the individual future choice probability of a kind of product using the following Logit Model.

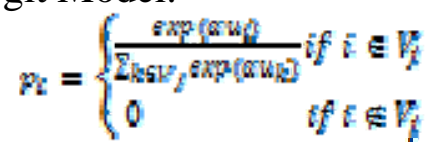

$V_{j}=$ A set of respondent $i$ 's purchasing probability from difference channel, here we define it as the business firms of commercial cluster where the respondents will purchase in the next year.

$u_{i}=$ Respondent $i$ 's purchasing probability from the business firms of commercial cluster, here we define it as the ratio between the purchasing quantity that respondents bought from business firms of commercial cluster and all the quantity that respondents bought from different channels.

$u_{k}=$ Respondent $i$ 's purchasing probability from various channel $\left(w_{[} w_{F_{R}}\right)$.

We can estimate the parameter $\alpha$ in Equation (8) by maximizing the following likelihood function:

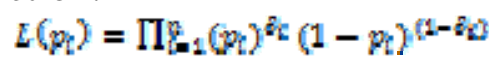

$$
\begin{aligned}
& \text { So, } \ln L\left(p_{l}\right)=\left[\ln \left(p_{l}{ }^{{ }_{1}}\right)+\cdots+\ln \left(p_{k}{ }^{{ }_{n}}\right)\right] \\
& +\left[\ln \left(1-p_{0}\right)\left(1-i_{1}\right)+\cdots\right] \\
& \text { Let } \frac{d \ln L p_{n}}{d p_{\mathrm{g}}}=0 \text {, }
\end{aligned}
$$

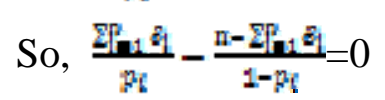

Here $\sigma_{i}$ equals 1 if respondent $i$ last purchased from business firms of commercial cluster and equals 0 otherwise.

So we can get the Maximizing Likelihood Estimation Value $p$ as formula (10).

$$
p=\frac{1}{n} \sum \sum_{1} \delta_{l}
$$

According to Binomial Logit Model:

$$
F_{i}=\frac{1}{1+\varepsilon^{-24}}
$$

Then, let $p_{\mathrm{l}}-p$, we can obtain parameter $\mathrm{x}$.

Here, $u_{i}, u_{k}$ and $\delta_{i}$ can be investigated with questionnaires and we can analyze $x$ with the 
data.

Therefore, base on parameter $x$ and $\varepsilon$, we can calculate $\Delta C$, and analyze the risk loss of demand fluctuation and the risk degree. Then we can estimate the actual risk of business model innovation bringing to commercial cluster.

\section{Analysis}

The approach to estimate the development risk of commercial cluster is necessary, especially in China. Because the commercial cluster of China differs from other countries'. At present, the commercial clusters are the critical part of supply chain in China, and most of manufacturers' distribution channels depend on the commercial clusters, and the business firms of commercial clusters as middlemen distribute the products to various regions and collect the marketing information for manufacturers. It is well known, China is a large country, and the consumers distributed in different areas, if there are no these middlemen, the manufacturers, especially small firms, can't invest so much for the marketing in a large market. But now it is changed, with the development of logistics industry and information technology, more and more retailers and clients purchase by online or other channels, and the developed logistics system will support the transaction well. Even though you live in a remote village, you can order by online or telephone, and the product will arrive at your appointed place in several days.

Although most manufacturers cooperate with middlemen sequentially, they choose some ebusiness firms, such as Tmall, 360buy. These firms are new kinds of e-business clusters, and they operate their business depending on modern logistics system and information technology to finish the transaction with consumers directly. This kind of business model also brings the traditional commercial clusters more threats directly or indirectly. With the increase of credit rating, more and more clients or consumers will prefer to this purchasing channel, and just for the clients or consumers' changing, more and more manufacturers will prefer to e-business firms as their middlemen to distribute the products.

In addition, some manufacturers also build up their direct sale system with the aid of logistics and information. They set up many direct sale branches in the market and supply their products to consumers directly by their inventory and distribution system. This way can interest consumers in their products, but its marketing cost is high and it decreases the company's revenue. To most manufacturers, they have no ability to operate with this method.

Now, the traditional commercial cluster was in trouble, but it doesn't means the commercial cluster faces to serious risk, at least in the near future it can't happen. Because the direct sale or ebusiness can't meet all consumers' needs at present, and the purchasing risk of online effect on clients or consumers' psychology, such as credit, quality, transaction time, etc. However, since the traditional commercial cluster faces to the risk, they have to prepare for it in advance, otherwise, once the risk becomes serious, it will bring them massive assault.

Consequently, the risk should cause our attention. In this paper we estimate the risk loss of demand fluctuation for the commercial cluster with Random Variation, and its main purpose is to test the loss that demand fluctuation brings to business firms of commercial cluster in the all supply chain. Then we adopt Logit Model and Maximum Likelihood Method to test the demand fluctuation for the commercial cluster. Although it is not serious risk at present, we attempt to find this approach to the commercial cluster to forecast the risk constantly, and when we find the risk is dangerous to development of commercial cluster, they should find ways to remove the trouble.

\section{Conclusion}

In China there are so many commercial clusters distributed in most of cities, and it is very important to the local economy. But it is a fatal risk to these traditional commercial clusters as soon as the logistics industry and information technology develop to a more perfect lever. To the local government, the business firms or the middlemen, they have to face to the fact in the future. Since it 
is inevitable, we should cognize the risk and prepare for meeting it.

Firstly, the participators should know the development trend of logistics and information technology. Only we understand it, we can know what and how change it will bring to our modern economy in the future.

Secondly, since realizing it will bring the traditional commercial clusters much risk, we should know how to get the risk degree. Maybe there are many methods to obtain the risk degree, but in this paper, the way of risk estimate is not only easy to understand, but also can get the right result by investigation data.

Thirdly, to develop continuously in the future, the commercial clusters should develop their competitive advantage to control their downstream market. Otherwise, as soon as lose the downstream market, the commercial cluster will be meaningful to exist. Base on this, they also need to develop their logistics and information service, and improve it for their sale step by step.

Finally, commercial cluster can't develop well without manufacture. Since it is obbligato part, the local government should actively guide the firms or the investors to invest in manufacture to support the local commercial cluster to sustainable development.

In this paper, our warning is only for China commercial cluster, and the approach to risk estimate is only give the operators of commercial cluster a basic advice to get the risk degree they face to. However, there is some limitation in our estimate process. We can't examine the approach by survey data, but we give the detail of the estimate process with mathematics, and we deduce the process step by step with the famous mathematical formulas, such as Random Variation Model, Logit Model, and Maximum Likelihood Model, because those reliable formulas support our research strongly, the risk estimate process is Scientific and effective. Meanwhile, critical point of risk degree is very important to the commercial cluster. It means which level of risk degree is dangerous to them should be researched in the future, and it is a complicated process, we hope it could be obtained base on the experiment in the near future.

\section{References}

[1]Tsay, A., N. Agrawal, Channel conflict and coordination in the E-commerce age, Production and Operations Management, 2004, 13(1): pp.93-10.

[2]Dumrongsiri Aussadavut, Ming Fan, Apurva Jain, Kamran Moinzadeh. A supply chain model with direct and retail channels. European Journal of Operational Research, 2008, 187(3): pp.691718.

[3]Paul Timmers, Business Models for Electronic Markets. Electronic Markets, 1998, 8(2): pp.3-8.

[4]Magretta, J. "Why Business Models Matter." Harvard Business Review, 2002, 80(5): 86-92.

[5]Henry Chesbrough and Richard S. Rosenbloom. The role of the business model in capturing value from innovation: evidence from Xerox Corporation's technology spin-off companies. Industrial and Corporate Change, 2002, 11(3): pp.529-555.

[6]Stephen Downing. The Social Construction of Entrepreneurship: Narrative and Dramatic Processes in the Coproduction of Organizations and Identities. Entrepreneurship Theory and Practice, March 2005, 29(2): pp.185-204.

[7]Osterwalder A., Pigneur Y., Tucci C. L.. Clarifying BMs: origins, present, and future of the concept. Communications of the Association for Information Systems, 2005, 16: pp.1-25.

[8]Mitchell, D., \& Coles, C. The ultimate competitive advantage of continuing business model innovation. Journal of Business Strategy, 2003, 24: pp.15-21.

[9]Chesbrough, H. W. Open innovation: The new imperative for creating and profiting from technology. Boston: Harvard Business School Press, 2003.

[10]Miles, R. E., Miles, G., \& Snow, C. C. Collaborative entrepreneurship: A business model for continuous innovation. Organizational Dynamics, 2006, 35: pp.1-11.

[11]Chesbrough, H. W. Business model innovation: Opportunities and barriers. Long Range Planning, 2010, 43: pp.354-363.

[12]Rivette, K. G., \& Kline, D. Discovering new value in intellectual property. Harvard Business Review, 2000, 78(1): pp.54-66. 
[13]Gambardella, A., \& McGahan, A. M. Business model innovation: General purpose technologies and their implications for industry structure. Long Range Planning, 2010, 43: pp.262-271.

[14]Boudreau, K. J., \& Lakhani, K. R. How to manage outside innovation. MIT Sloan Management Review, 2009, 50(4): pp.69-76.

[15]Demil, B., \& Lecocq, X. Business model evolution: In search of dynamic consistency. Long Range Planning, 2010, 43: pp.227-246.

[16]Johnson, M. W., Christensen, C. C., \& Kagermann, H. Reinventing your business model. Harvard Business Review, 2008, 86(12): pp.50-59.

[17]Sosna, M., Trevinyo-Rodríguez, R. N., \& Velamuri, S. R. Business models innovation through trial-and-error learning: The Naturhouse case. Long Range Planning, 2010, 43: pp.383-407.

[18]Chesbrough, H. W. Business model innovation: Opportunities and barriers. Long Range Planning, 2010, 43: pp.354-363.

[19]Hayashi, A. M. Do you have a plan “B”? MIT Sloan Management Review, 2009, 51(1): pp.1011.

[20]McGrath, R. G. Business models: A discovery driven approach. Long Range Planning, 2010, 43: pp.247-261.

[21]Sheehan, N. T., \& Stabell, C. B. Discovering new business models for knowledge intensive organizations. Strategy and Leadership, 2007, 35: pp.22-29.

[22]Svejenova, S., Planellas, M., \& Vives, L. An individual business model in the making: A chef's quest for creative freedom. Long Range Planning, 2010, 43: pp.408-430.

[23]Doz, Y. L., \& Kosonen, M. Embedding strategic agility. Long Range Planning, 2010, 43: pp.370-382.

[24]Smith, W. K., Binns, A., \& Tushman, M. L. Complex business models: Managing strategic paradoxes simultaneously. Long Range Planning, 2010, 43: pp.448-461.

[25]Santos, J., Spector, B., \& Van Der Heyden, L. 2009. Toward a theory of business model innovation within incumbent firms. Working paper No. 009/16/EFE/ST/TOM, INSEAD, Fontainebleau, France.

[26]Nissan Levin, Jacob Zahavi. Continuous predictive modeling-A comparative analysis. Journal of Interactive Marketing, Spring 1998, 12(2): pp.5-22. 